\title{
A rare case of metachronous neuroendocrine tumor after a colorectal adenocarcinoma: qualitative critical review of synchronous and metachronous gastrointestinal NET
}

\author{
Francesco Lancellotti ${ }^{1}$ - Luigi Solinas ${ }^{2} \cdot$ Davide Telesco $^{3} \cdot$ Andrea Sagnotta $^{2} \cdot$ Augusto Belardi $^{2}$. \\ Giuseppina Balsamo ${ }^{4}$. Stefano Mancini ${ }^{2}$
}

Received: 25 June 2020 / Accepted: 19 September 2020 / Published online: 12 October 2020

(c) The Author(s) 2020

\begin{abstract}
Gastrointestinal neuroendocrine tumor (NET) associated with a metachronous intestinal adenocarcinoma is rare. We report the case of a 71-year-old man with an ileal NET. Patient has previously undergone a left colectomy for sigmoid cancer. We report a complete review both of the metachronous and synchronous NET. A comprehensive systematic literature search in PubMed, EMBASE, and MEDLINE identified a total of 35 relevant studies. This study includes an analysis of review articles, case reports, case series, retrospective studies and population-based studies. In the English literature to date, there are 21 case reports (19 synchronous cases and 2 metachronous cases), 3 case series and 3 review articles, and less than 10 retrospective studies or population-based studies. A total of 31 patients in 24 articles were included in the study: 28 patients with a synchronous gastrointestinal NET and colorectal adenocarcinoma and 3 patients with metachronous gastrointestinal NET and colorectal adenocarcinoma. The incidence of synchronous cancer (particularly for colorectal and gastric cancer) with a gastrointestinal NET ranges from 10 to 50\%, while for the metachronous ones it is still unclear. This is the third metachronous case report and the first descriptive case of gastrointestinal NET diagnosed 2 years after a colorectal adenocarcinoma. An endoscopic follow-up program for gastrointestinal NET patients and/or for first-degree relatives of NET patients appears recommendable.
\end{abstract}

Keywords Metachronous neuroendocrine $\cdot$ Synchronous NET · Colorectal adenocarcinoma $\cdot$ Coexisting tumors · Gastrointestinal carcinoids

\section{Background}

Neuroendocrine tumors of the small intestine (ileal NETs) represent the most common small-bowel neoplasms (31-41\% of all small-bowel malignancies), $13 \%$ of all NETs

Francesco Lancellotti

francesco.lancellotti87@gmail.com

Luigi Solinas

luigi73solinas@gmail.com

Davide Telesco

davide.telesco@gmail.com

Andrea Sagnotta

andrea.sagnotta@gmail.com

Augusto Belardi

augustobelardi@hotmail.com

Giuseppina Balsamo

giuseppina.balsamo@alice.it and $40 \%$ of the gastrointestinal NETs [1,2]. The incidence is estimated at about 1-2 cases/100,000 inhabitants/year [3].

The most frequent NET location is the terminal part of the small intestine [4], in particular the last $60 \mathrm{~cm}$, and in $33 \%$ of the cases they are multiple along with the tenuous

Stefano Mancini

Stefano.mancini@aslroma1.it

1 Department of Surgical Sciences, Sapienza University of Rome, Rome, Italy

2 Department of General Surgery and Surgical Oncology, San Filippo Neri Hospital, Rome, Italy

3 Department of General Surgery, Surgical Specialities "Paride Stefanini”, Sapienza University of Rome, Rome, Italy

4 Department of Clinical Pathology, San Filippo Neri Hospital, Rome, Italy 
[5]. They can remain asymptomatic until the appearance of metastases, or they can cause anemia and/or obstructive symptoms, from transient abdominal pain to occlusion due to stenosis or intestinal intussusception. The survival at 5 years after diagnosis of NET of the non-metastatic small intestine is $65 \%$ [4].

Several population-based studies show that patients with gastrointestinal NETs may have an associated metachronous primary tumor and vice versa [6]. The literature reports only two cases of metachronous NET.

We describe herein the third case of metachronous ileal NET and report a complete review both of the metachronous and synchronous NET.

\section{Case presentation}

A 71-year-old Caucasian man with a significant past medical history for cholecystectomy, ex-smoker, obese (BMI 32.4) came to the emergency room with a 2-week history of intermittent pain in the left quadrant of the abdomen. Flexible colonoscopy was performed for further evaluation that showed large stenosing polyps in the sigmoid. Pathological finding revealed dysplasia associated with differentiated invasive adenocarcinoma. CT abdomen showed sub-stenosing mass in the left colon; no lesions in the small bowel and/or hepatic nodules were revealed.

Thus, he underwent left colectomy for sigmoid neoplasm in June 2018. The histologic examination revealed a villous tubular adenoma with low-grade dysplasia, focally highgrade with foci of adenocarcinoma associated with highgrade tumour budding (UICC 2012: pT1 pN0 M0) (Fig. 1).

In January 2020, the patient was admitted to our Department of General Surgery with a 3-week history of sub-occlusive episodes with nausea, recurrent episodes of constipation and epigastric abdominal pain.

CT scan showed hydro-aero levels in the upper abdominal and mesogastric quadrants, and last loops grouped by thickened walls with a $3 \mathrm{~cm}$ solid nodule with multiple small surrounding reactive lymph nodes.

The entero-MRI showed a $3 \mathrm{~cm}$-vascularized formation within the mesentery not in contact with tenuous loops, and two vascularized locations of $2.6 \mathrm{~cm}$ and $1.6 \mathrm{~cm}$ within the wall of the distal ileal tract (Fig. 2).

At the operation, the wall of the ileal loop was thick and fibrous with numerous tenacious viscera-wall and viscera-viscera adhesions. A viscerolysis and an ileal resection were performed. Patient was discharged in 7 POD with an unremarkable post-operative course. The
Fig. 1 Photomicrographs of resected specimen (adenocarcinoma). Note the foci of adenocarcinoma associated with high-grade tumour budding in a (haematoxylin and eosin $\times 40$ ). In $\mathbf{b}$, magnification $\times 100$ showing a component of villous tubular adenoma with low-grade dysplasia, focally high-grade (haematoxylin and eosin).
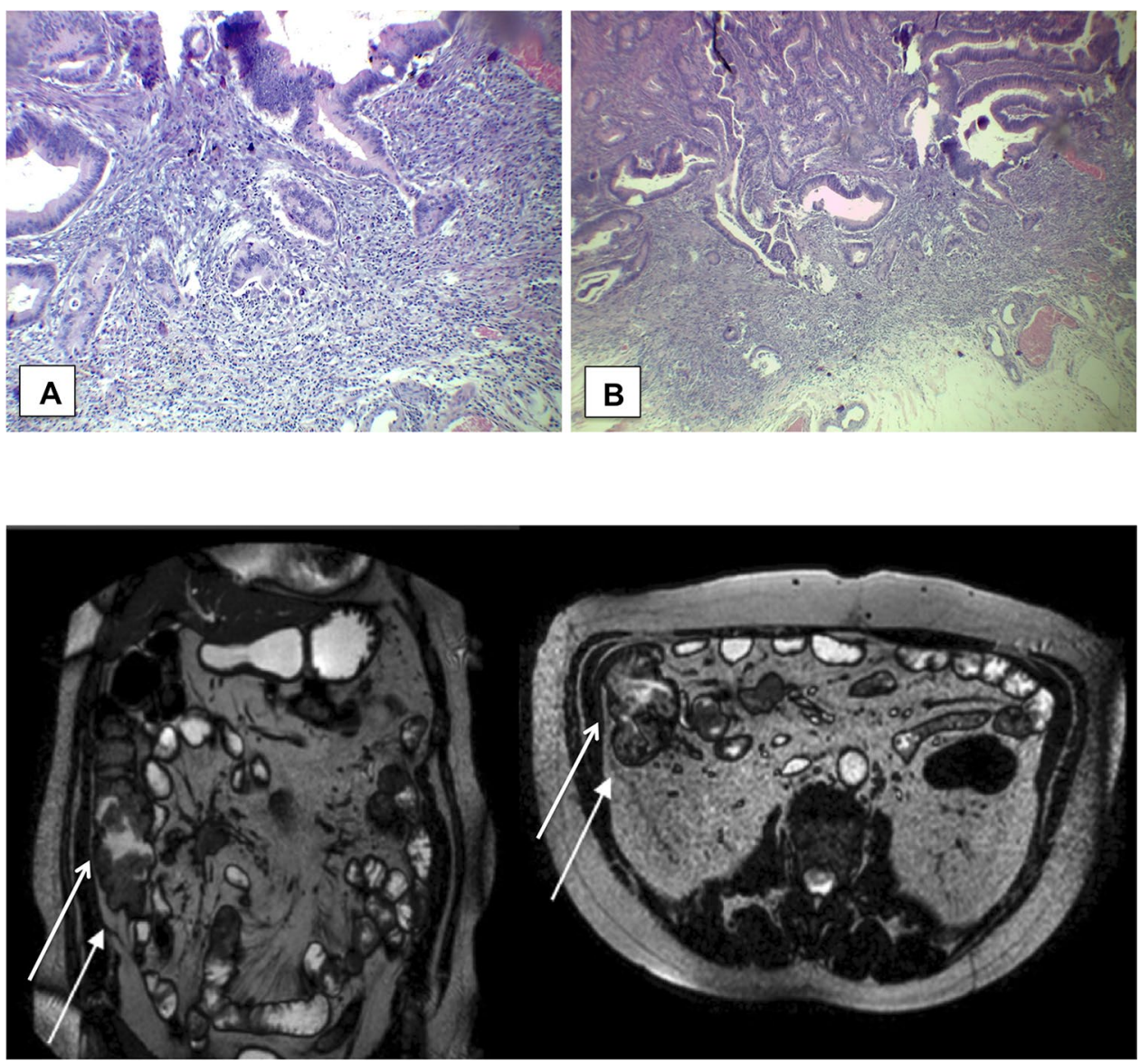

Fig. 2 Pre-operative MRI shows a nodule within the wall of the distal ileal (arrow) and within the mesentery. Coronal (left) and axial plane (right) 
histologic examination (Fig. 3) revealed a well-differentiated neuroendocrine tumour of the distal ileum (carcinoid, NET G1 sec. WHO 2010) pT3-stage I sec. UICC 2009) G1 pT3 pN2 pMx sec AJCC 8TH edition 2017. Ki67/MIB-1 <3\%, CK7-; CK20-; CD56+; NSE+; Synaptophysin+; Chromogranin A+.

\section{Methods}

A comprehensive systematic literature search was carried out in PubMed, EMBASE, and MEDLINE to identify relevant articles. The MeSH terms were "NET", "neuroendocrine tumor", "carcinoid", and "small intestinal carcinoids", combined with MeSH terms "colorectal adenocarcinoma", or "colorectal tumor" as well as "colonic tumor", "synchronous" and "metachronous". The relevant reference lists of articles were also searched manually for additional works. Two different researchers carried out the search independently. The last search was performed in the first half of April 2020. Articles were limited to manuscript publications in the English language and/or all abstract publications. A total of 35 relevant studies were found and examined. This study includes an analysis of review articles, case reports, case series, retrospective studies and population-based studies.

\section{Results}

To date, the literature in English reveals, 20 case reports (18 synchronous cases [7-24], 2 metachronous cases [25, 26]), 2 case series [25, 27], 3 review articles [28-30], and about 10 retrospective studies [31-34] or population-based studies from a National Registry [35-41] of synchronous or metachronous NET with a second primary malignancy (SPM). A total of 31 patients in 24 articles were included in the study: 28 patients with a synchronous gastrointestinal NET and colorectal adenocarcinoma (Table 1) and 3 patients (including the present study) of 3 articles with metachronous gastrointestinal NET and colorectal adenocarcinoma (Table 2).

Mean patient age was 65.5 years (range $38-90$ years), by gender there were 12 females (39\%) and 19 males (61\%), undergoing gastrointestinal surgery.

The adenocarcinoma location was: sigmoid colon (35.5\%, 11 patients), right colon ( $25.8 \%, 8$ patients), rectum (12.9\%, 4 patients), left colon (9.7\%, 3 patients), hepatic flexure (6.5\%, 2 patients), splenic flexure (3.2\%, 1 patient), transverse colon $(3.2 \%, 1$ patient), and small bowel $(3.2 \%, 1$ patient). In all the cases the tumor was resectable. NET location was: small bowel $(67.8 \%, 21$ patients), rectum $(22.6 \%$, 7 patients), left colon (3.2\%, 1 patient), stomach (3.2\%, 1 patient) and duodenum (3.2\%, 1 patient).

In all synchronous cases, symptoms and signs were related to the adenocarcinoma, while NET was often asymptomatic.
Fig. 3 Photomicrographs of the resected specimen. Note the organoid and trabecular patterns of the NET cells (a), (haematoxylin and eosin staining, original magnification $\times 400$ ). Chomogranin stains of the resected NET (b). Antigen ki-67 immunostaging was positive in $3 \%$ of tumor cells (c). Positivity for CD56 in photo d
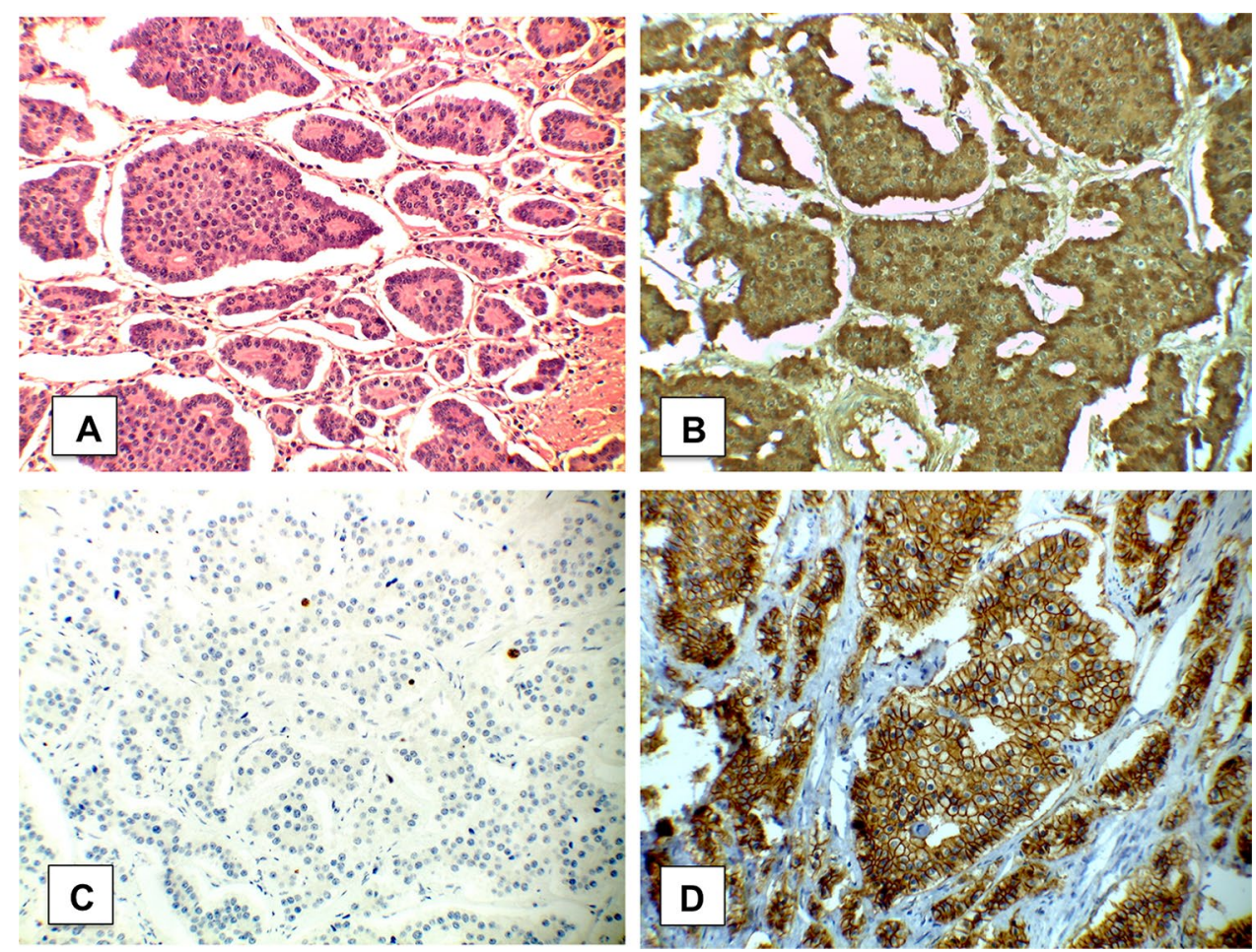
Table 1 Literature review of synchronous cases with both gastrointestinal adenocarcinoma and gastrointestinal NET
Table 2 Literature review of metachronous cases with both gastrointestinal adenocarcinoma and gastrointestinal NET

\begin{tabular}{|c|c|c|c|c|c|c|}
\hline Study & Year & Age & Sex & Carcinoma location & Net location & Grading \\
\hline Pearson and Fitzgerald [27] & 1949 & 88 & M & Left colon & Small bowel & - \\
\hline Pearson and Fitzgerald [27] & 1949 & 73 & M & Sigmoid colon & Stomach & - \\
\hline Pearson and Fitzgerald [27] & 1949 & 61 & $\mathrm{~F}$ & Left colon & Small bowel & - \\
\hline Khubchandani et al. [7] & 1972 & 53 & M & Rectum & Rectum & - \\
\hline Lotlikar et al. [25] & 1981 & 53 & M & Rectum & Small bowel & - \\
\hline Lotlikar et al. [25] & 1981 & 67 & $\mathrm{~F}$ & Right colon & Small bowel & - \\
\hline Lotlikar et al. [25] & 1981 & 60 & $\mathrm{~F}$ & Sigmoid colon & Small bowel & - \\
\hline Sacchi et al. [8] & 1988 & 57 & M & Right colon & Small bowel & - \\
\hline Tse et al. [9] & 1997 & 72 & M & Hepatic flexure & Small bowel & - \\
\hline Habal et al. [28] & 2000 & 52 & M & Sigmoid colon & Rectum & \\
\hline Cioffi et al. [10] & 2005 & 64 & $\mathrm{~F}$ & Ileum & Small bowel & - \\
\hline Klucinski et al. [11] & 2006 & 72 & $\mathrm{~F}$ & Transverse colon & Small bowel & - \\
\hline Chemli et al. [12] & 2007 & 63 & $\mathrm{~F}$ & Right colon & Small bowel & - \\
\hline Aslam et al. [13] & 2009 & 67 & $\mathrm{~F}$ & Sigmoid colon & Small bowel & G1 \\
\hline Boland et al. [14] & 2009 & 77 & $\mathrm{~F}$ & Left colon & Meckel's diverticulum & - \\
\hline McHugh et al. [15] & 2009 & 74 & $\mathrm{~F}$ & Rectum & Small bowel & - \\
\hline Wohadlo et al. [29] & 2011 & 53 & M & Splenic-hepatic flexure & Small bowel & - \\
\hline Gurzu et al. [16] & 2012 & 78 & $\mathrm{~F}$ & Sigmoid colon & Small bowel & G3 \\
\hline Pozzato et al. [17] & 2012 & 61 & M & Right colon & Duodenum & G1 \\
\hline Katalinic 2014 et al. [18] & 2014 & 63 & M & Right colon & Meckel's diverticulum & G1 \\
\hline Zhu et al. [19] & 2015 & 64 & $\mathrm{~F}$ & Rectum & Rectum & G1 \\
\hline Almajano et al. [20] & 2016 & 66 & M & Right colon & Small bowel & G1 \\
\hline Mohapatra et al. [21] & 2016 & 83 & M & Sigmoid colon & Left colon & G3 \\
\hline Nejatollahi et al. [22] & 2016 & 83 & M & Sigmoid colon & Small bowel & G1 \\
\hline Vootla et al. [23] & 2016 & 46 & $\mathrm{~F}$ & Hepatic flexure & Rectum & G1 \\
\hline Winn et al. [30] & 2017 & 40 & M & Sigmoid colon & Rectum & G1 \\
\hline Winn et al. [30] & 2017 & 70 & M & Sigmoid colon & Rectum & G1 \\
\hline Napolitano et al. [24] & 2017 & 72 & M & Right colon & Small bowel & G1-G2 \\
\hline
\end{tabular}

NET neuroendocrine tumour

\begin{tabular}{lccllll}
\hline Study & Age & Sex & Carcinoma location & Net location & Presentation & $\begin{array}{l}\text { Time } \\
\text { interval } \\
\text { (years) }\end{array}$ \\
\hline Lotlikar et al. [25] & 38 & M & Right colon & Small bowel & NET before & 4 \\
Fujimoto et al. [26] & 90 & M & Sigmoid colon & Rectum & Carcinoma before & 2 \\
Present study & 71 & M & Sigmoid colon & Small bowel & Carcinoma before & 2 \\
\hline
\end{tabular}

NET neuroendocrine tumour

\section{Discussion}

We performed a comprehensive systematic literature search was carried out and summarized the reported cases with both synchronous gastrointestinal NET and colorectal adenocarcinoma in Table 1, and the metachronous ones in Table 2. The case reports of synchronous tumors are more common than metachronous ones. In all cases, symptoms and signs were probably related to the adenocarcinoma instead of NETs. The tumors were in all cases resectable. The most frequent carcinoma location was the sigmoid colon, while the most frequent small intestinal NET location was the small bowel. In three cases, the tumor was multifocal: in two cases [9, 15] there were two foci of small intestinal NETs in the small bowel, in one case [29] there were two small intestinal NETs in the small bowel and two carcinomas in the colon. Pearson and Fitzgerald were the first to report the high incidence (23\%) of second primary malignancies (SPM) in patients with small intestinal NETs at autopsy [27]. A certain number of NETs were incidentally found during surgery for other 
cancers. The estimated rate of SPM associated with other malignancies was $2.3 \%$ in surgical cases and $8.1 \%$ in autopsy cases [42].

The literature in English contains several reviews. Habal et al. collected a large series of cases: over 5000 cases in about 14 articles, including autopsy studies and cases collected by files at Cancer registry resources [28]. They found that small-bowel small intestinal NETSs had the highest rate of SPM (29-52\%), followed by appendiceal (13-32\%) and colorectal small intestinal NETs (5-32\%), and that most of SPM and small intestinal NETs were synchronous (59-87\%). In a report from the SEER database (Surveillance, Epidemiology and End Results Program, National Cancer Institute, USA), $29 \%$ of patients with gastrointestinal small intestinal NET had an additional malignancy [41].

The first studies investigating the incidence of additional primary cancers among patients with NETs were autopsy studies $(31,36)$, while in recent years population-based studies in the National Registry have increased [35-41]. Zar et al. used the Swedish Cancer Registry to estimate excess risk of second primary malignancies among 3741 small intestinal NET (SINET) patients [37].

A very interesting article was published by Amin et al.: it is the first study that used the US-based SEER database in the USA, and the first to quantify prognoses and predictors of additional malignancies in SINET patients [38]. They also quantified the risk of developing SINET, both future primaries after SINET (post-SINET) as well as the risk of future SINET among patients with non-SINET primaries (pre-SINET).

Kamp et al. and Clift et al. found that the only significantly elevated risk of SPM was for synchronously diagnosed neoplasms [32, 33]. There were no statistical differences between observed and expected occurrences of SPM in their previous and metachronous subsets.

In 2014, Kauffmann et al. conducted a population-study using the Surveillance and Epidemiology, and End Results (SEER) database, an even bigger one [40]. They identified a cohort of 9727 patients with pancreatic NET (PNET) or gastrointestinal NET (GINET) and found an incidence of additional malignancies of $25.8 \%$. Patients with GINET had an increased risk of additional malignancies, particularly for colorectal and gastric cancer, whereas patients with PNET had a decreased risk of a second malignancy compared with the general population.

Thus, synchronous malignancies with NETs are more common than metachronous cases [28, 38, 43], but metachronous malignancies can occur anywhere [28, 39, 44]. Metachronous tumors can occur 1-7 years after the NET is diagnosed [45]. Except for the autopsy studies and population-based study, in the literature in English there are only two case reports about metachronous NET with a SPM $[25,26]$. In our study, we present the third metachronous case report and the first descriptive case of gastrointestinal NET diagnosed 2 years after a colorectal adenocarcinoma.

Concerning the prognosis, Amin et al. demonstrated that patients diagnosed with a carcinoma before their SINET (subgroup pre-SINET) have a worse prognosis than patients diagnosed with SINET as a cancer of first diagnosis (subgroup post-SINET), mean survival 57.9 vs 40.9 months [38]. Several studies agree that the overall prognosis depends primarily on the more aggressive SPM [16, 28]. In fact, in only one of the 270 cases analyzed by Berner, the NET itself changed the prognosis [46].

Many hypotheses have been advanced to explain the pathogenesis of association between NETs and second primary malignancy: a genetic predisposition, common environmental exposures or behavioral risk factors, exogenous mitogenic effects of secretory products from a primary tumor causing neoplastic transformation, or a combination of all these factors [41, 47]. The population-based study by Kharazmi et al., using the nationwide family cancer data sets of Sweden and Finland, found that first-degree relatives of patients with gastrointestinal NET had an increased risk of developing these tumors, thus suggesting a potential counseling for this population [48]. Ito et al. [49] conducted a nationwide survey to examine the epidemiology of GINETs in Japan, showing that incidence of new-onset PNET in 2005 was approximately 1.01 per 100,000 population in Japan, which was approximately three times the annual incidence of new-onset PNET in the United States. Five years later, the same group clarified some epidemiological changes [50]: they found that incidences of GINET in Japan were lower than those reported in Western nations, but similar than those reported in China, Taiwan and Korea, suggesting ethnic differences.

In 2013, Shenoy described a case series of 11 patients with gastrointestinal cancers and synchronous NET, but no metachronous tumors. All patients presented a pattern of similar embryonic visceral origin, thus suggesting that SINET may produce growth factors and exert a paracrine effect that may increase a person's predisposition to local colorectal adenocarcinoma [51]. SINETs also produce non-neuroendocrine peptides that may play a role in carcinogenesis as growth factors. Their principal role is to regulate cell growth and differentiation [52, 53]. Recently, PDGF, EGF, TGF, insulin-like growth factors, and FGF have been demonstrated in gastrointestinal NETs [54], and these growth factors may play a central role in the genesis of SPMs in patients with NETs. In fact, over 30 other peptides have been isolated from neuroendocrine cells. It is plausible that many of these peptides may play similar roles in tumorigenesis. It is also possible that the increased risk of a second cancer in patients with gastrointestinal NET is related to common genetic or tumorigenic pathways. There is a growing body of literature that reports an 
increased incidence of other malignancies in patients with gastrointestinal NETs in absence of a known genetic syndrome. This may indicate still-unknown genetic mutations predisposing to multiple malignancies [28, 39]. Finally, the interaction between environmental and genetic factors and/or treatment-related or lifestyle factors such as smoking and alcohol may promote the carcinogenesis of second cancers after NETs [35].

This qualitative and critical review underscores the importance of increased surveillance for other malignancies in patients with gastrointestinal NET. Although enrolment in follow-up programs (such as colonoscopy or gastroscopy) cannot be ascertained from the SEER database, case reports or article reviews, a closer surveillance than that of the general population can be recommended for NET patients and/ or first-degree relatives of NET patients.

\section{Conclusion}

In our study, we present the third metachronous case report and the first descriptive case of gastrointestinal NET diagnosed 2 years after a colorectal adenocarcinoma. In retrospective and population-based studies, the incidence of synchronous cancer (particularly for colorectal and gastric cancer) with a gastrointestinal NET range from 10 to $50 \%$ is found, for the metachronous' cancer it is still unclear if there is a direct connection or a genetic predisposition. The underlying pathogenesis may be a combination of factors, such as genetic predisposition, common environmental exposure or behavioral risk factors and/or exogenous mitogenic effects of secretory products from a primary tumor. Therefore, at the present state of the art, it is impossible to draw up guidelines on this issue, but an endoscopic follow-up program for gastrointestinal NET patients and/or for first-degree relatives of NET patients appears recommendable for early detection of a synchronous second gastrointestinal cancer. However, this study does not support extensive screening programs for metachronous second primary malignancies in NET patients.

\footnotetext{
Author contributions All authors provided an intellectual contribution to this manuscript. FL literature search, data collection and interpretation, wrote the manuscript. LS study design and manuscript preparation. DT data collection and interpretation. AS and AB manuscript preparation. GB analysed and interpreted the pathology data. SM reviews the definitive manuscript. All authors read and approved the final manuscript.
}

Funding Open access funding provided by Università degli Studi di Roma La Sapienza within the CRUI-CARE Agreement.

\section{Compliance with ethical standards}

Conflict of interest Francesco Lancellotti, Luigi Solinas, Davide Telesco, Andrea Sagnotta, Augusto Belardi, Giuseppina Balsamo, Stefano Mancini declare that they have no conflict of interest.

Human rights All procedures followed have been performed in accordance with the ethical standards laid down in the 1964 Declaration of Helsinki and its later amendments.

Informed consent Informed consent was obtained from all patients for being included in the study.

Open Access This article is licensed under a Creative Commons Attribution 4.0 International License, which permits use, sharing, adaptation, distribution and reproduction in any medium or format, as long as you give appropriate credit to the original author(s) and the source, provide a link to the Creative Commons licence, and indicate if changes were made. The images or other third party material in this article are included in the article's Creative Commons licence, unless indicated otherwise in a credit line to the material. If material is not included in the article's Creative Commons licence and your intended use is not permitted by statutory regulation or exceeds the permitted use, you will need to obtain permission directly from the copyright holder. To view a copy of this licence, visit http://creativecommons.org/licenses/by/4.0/.

\section{References}

1. Bilimoria KY, Bentrem DJ, Wayne JD, et al. Small bowel cancer in the United States: changes in epidemiology, treatment, and survival over the last 20 years. Ann Surg. 2009;249:63-71.

2. Hatzaras I, Palesty JA, Abir F, et al. Small-bowel tumors: epidemiologic and clinical characteristics of 1260 cases from the Connecticut tumor registry. Arch Surg. 2007;142:229-35.

3. Modlin IM, Lye KD, Kidd M. A 5-decade analysis of 13,715 carcinoid tumors. Cancer. 2003;97:934.

4. Modlin IM, Champaneria MC, Chan AK, et al. A three-decade analysis of 3,911 small intestinal neuroendocrine tumors: the rapid pace of no progress. Am J Gastroenterol. 2007;102:1464-73.

5. Burke AP, Thomas RM, Elsayed AM, et al. Carcinoids of the jejunum and ileum: an immunohistochemical and clinicopathologic study of 167 cases. Cancer. 1997;79:1086-93.

6. Sunil A, Richard RPW, Steven HI, et al. The risk of metachronous cancers in patients with small-intestinal carcinoid tumors: a US population-based study. Endocr Relat Cancer. 2012;19:381-7.

7. Khubchandani M, Alford JE. Primary carcinoid and carcinoma of the rectum occurring simultaneously: report of a case. Dis Colon Rectum. 1974;17:117-22.

8. Sacchi G, Falchetti M, Fiorentino M, et al. Synchronous multiple primary malignant neoplasm of the gastro intestinal tract: carcinoid of the midgut and adenocarcinoma of the ascending colon. Pathologica. 1988;80:583-93.

9. Tse V, Lochhead A, Adams W, et al. Concurrent colonic adenocarcinoma and two ileal carcinoids in a 72-year-old male. Aust N Z J Surg. 1997;67:739-41.

10. Cioffi U, De Simone M, Ferrero S, et al. Synchronous adenocarcinoma and carcinoid tumor of the terminal ileum in a Crohn's disease patient. BMC Cancer. 2005;5:157.

11. Kuciński A, Pawłowski W, Krasnodębski IW. Synchronous intestinal tumours coexisting with adenocarcinoma transverse colon 
and small intestine carcinoid. Gastroenterol Rev. 2006;1:126-8 (in Polish).

12. Chemli S, Dhouib RS, Mrad K, et al. Association synchrone carcinoide ileal et carcinome recto-colique. A propos d'un cas [Synchronous association of ileal carcinoid and colorectal carcinoma. A case report]. Tunis Med. 2007;85:607-9.

13. Aslam MI, Salha IB, Muller S, et al. Synchronous ileal carcinoid and primary colonic neoplasms: a case report. Cases J. 2009;2:8317

14. Boland BM, Collins CG, Christiansen E, et al. Three synchronous gastrointestinal tumours. Ir J Med Sci. 2011;180:897-900.

15. McHugh SM, O’Donnell J, Gillen P. Synchronous association of rectal adenocarcinoma and three ileal carcinoids: a case report. World J Surg Oncol. 2009;7:21.

16. Gurzu S, Bara T Jr, Bara T, et al. Synchronous intestinal tumors: aggressive jejunal carcinoid and sigmoid malignant polyp. Rom J Morphol Embryol. 2012;53:193-6.

17. Pozzato P, Casadei GP, Fornelli A, et al. Synchronous association of two neuroendocrine gastroenteropancreatic tumors, an adenocarcinoma of the cecum, and a Meckel's diverticulum: a case report. Tumori. 2012;98:e16-e1717.

18. Katalinic D, Santek F, Juretic A, et al. Gastroenteropancreatic neuroendocrine tumour arising in Meckel's diverticulum coexisting with colon adenocarcinoma. World J Surg Oncol. 2014;12:358.

19. Zhu JG, Zhang ZT, Wu GC, et al. Synchronous collision neuroendocrine tumor and rectal adenocarcinoma: a case report. Indian J Surg. 2015;77:185-7.

20. Alfaro Almajano E, Bengochea Martínez L, Mateos Barrionuevo FJ, et al. Tumor neuroendocrino bien diferenciado ileal y adenocarcinoma de colon sincrónicos: a propósito de un caso y revisión de la literatura [Synchronous well differentiated ileal neuroendocrine tumour and colonic adenocarcinoma. A case report and a review of the literature]. Rev Esp Patol. 2018;51:14-7.

21. Mohapatra S, Ibrarullah M, Mohapatra A, et al. Synchronous adenocarcinoma and neuroendocrine carcinoma of the colon: a case report. J Surg Case Rep. 2016;2016:rjw042.

22. Nejatollahi SM, Etemad O. Concurrent occurrence of tumor in colon and small bowel following intestinal obstruction: a case report and review of the literature. Case Rep Surg. 2016;2016:8591697.

23. Vootla V, Ahmed R, Niazi M, et al. Synchronous adenocarcinoma of the colon and rectal carcinoid. Case Rep Gastroenterol. 2016;10:600-4.

24. Napolitano L, D'Alessandro V, Risio D, et al. Association between neuroendocrine tumor of the ileum and two colonic primary malignancies. A case report and review of literature. Ann Ital Chir. 2017;6:S2239253X17024847

25. Lotlikar U, Fogler R, Novetsky AD, et al. Concurrent colonic carcinoma and small-bowel carcinoid tumor. Case reports and review of the literature. Dis Colon Rectum. 1982;25:375-82.

26. Fujimoto T, Konno S, Usuda A, et al. A case of rectal neuroendocrine carcinoma that developed two years after curative resection for sigmoid colon cancer. Gan To Kagaku Ryoho. 2019;46:727-9.

27. Pearson CM, Fitzgerald PJ. Carcinoid tumors; a reemphasis of their malignant nature; review of 140 cases. Cancer. 1949;2:1005-266.

28. Habal N, Sims C, Bilchik AJ. Gastrointestinal carcinoid tumors and second primary malignancies. J Surg Oncol. 2000;75:306.

29. Wohadlo Ł, Darasz Z, Wysocki W. Multifocal colorectal adenocarcinoma with a synchronous multifocal carcinoid of the small intestine-case report and literature review. Pol Przegl Chir. 2011;83:562-7.

30. Winn JN, Sathyamurthy A, Kneib JL, et al. Synchronous gastrointestinal carcinoid tumor and colon adenocarcinoma: case reports and literature review. Am J Case Rep. 2017;18:626-30.
31. Gerstle JT, Kauffman GL Jr, Koltun WA. The incidence, management, and outcome of patients with gastrointestinal carcinoids and second primary malignancies. J Am Coll Surg. 1995;180:427-32.

32. Kamp K, Damhuis RAA, Feelders RA, et al. Occurrence of second primary malignancies in patients with neurodendocrine tumors of the digestive tract and pancreas (GEP-NET). Endocr Relat Cancer. 2012;19:95-9.

33. Clift AK, Drymousis P, Al-Nahhas A, et al. Incidence of second primary malignancies in patients with neuroendocrine tumours. Neuroendocrinology. 2015;102:26-322.

34. Verrico M, Rossi L, Tomao S, et al. Metachronous and synchronous cancers in patients with neuroendocrine tumors. Oncology. 2020;98:10-5.

35. Tsai HJ, Wu CC, Tsai CR, et al. Second cancers in patients with neuroendocrine tumors. PLoS ONE. 2013;8:e86414.

36. Alexander JW, Altemeier WA. Association of primary neoplasms of the small intestine with other neoplastic growths. Ann Surg. 1968;167:958-63.

37. Zar N, Garmo H, Holmberg L, et al. Risk of second primary malignancies and causes of death in patients with adenocarcinoma and carcinoid of the small intestine. Eur J Cancer. 2008;44:718-25.

38. Amin S, Warner RR, Itzkowitz SH, et al. The risk of metachronous cancers in patients with small-intestinal carcinoid tumors: a US population-based study. Endocr Relat Cancer. 2012;19:381-7.

39. Tichansky DS, Cagir B, Borrazzo E, et al. Risk of second cancers in patients with colorectal carcinoids. Dis Colon Rectum. 2002;45:91-7.

40. Kauffmann RM, Wang L, Phillips S, et al. Incidence of additional primary malignancies in patients with pancreatic and gastrointestinal neuroendocrine tumors. Ann Surg Oncol. 2014;21:3422-8.

41. Modlin IM, Oberg K, Chung DC, et al. Gastroenteropancreatic neuroendocrine tumours. Lancet Oncol. 2008;9:61-72.

42. Moertel CG, Sauer WG, Dockerty MB, et al. Life history of the carcinoid tumor of the small intestine. Cancer. 1961;14:901-12.

43. Cokmert S, Demir L, Akder Sari A, et al. Synchronous appearance of a high-grade neuroendocrine carcinoma of the ampulla of vater and sigmoid colon adenocarcinoma. Case Rep Oncol Med. 2013;2013:930359.

44. Aggarwal G, Obideen K, Wehbi M. Carcinoid tumors: what should increase our suspicion? Clevel Clin J Med. 2008;75:849-55.

45. Kothari T, Mangla J. Malignant tumors associated with carcinoid tumors of the gastrointestinal tract. J Clin Gastroenterol. 1981;3:43-6.

46. Berner M. System carcinoid tumor and synchronous malignant tumors. Schweiz Med Wochenschr. 1993;123:594-9.

47. Neugut AI, Robinson E. Multiple primary neoplasms. Cancer J. 1992;5:245-8.

48. Kharazmi E, Pukkala E, Sundquist K, et al. Familial risk of small intestinal carcinoid and adenocarcinoma. Clin Gastroenterol Hepatol. 2013;11:944-9.

49. Ito T, Sasano H, Tanaka M, et al. Epidemiological study of gastroenteropancreatic neuroendocrine tumors in Japan. J Gastroenterol. 2010;45(2):234-43.

50. Ito T, Igarashi H, Nakamura K, et al. Epidemiological trends of pancreatic and gastrointestinal neuroendocrine tumors in Japan: a nationwide survey analysis. J Gastroenterol. 2015;50(1):58-64.

51. Shenoy S. Gastrointestinal carcinoids and colorectal cancers: is it a paracrine effect? Tumori J. 2013. https://doi. org/10.1700/1361.15111.

52. Waldum HL, Brenna E, Sandvik AK. Relationship of ECL cells and gastric neoplasia. Yale J Biol Med. 1998;71:325-35.

53. Chaudhry A, Funa K, Oberg K. Expression of growth factor peptides and their receptors in neuroendocrine tumors of the digestive system. Acta Oncol. 1993;32:107-14. 
54. Chaudhry A, Oberg K, Gobl A, et al. Expression of transforming growth factors beta 1, beta 2, beta 3 in neuroendocrine tumors of the digestive system. Anticancer Res. 1994;14(5B):2085-91.
Publisher's Note Springer Nature remains neutral with regard to jurisdictional claims in published maps and institutional affiliations. 